\title{
UM PARADIGMA DA QUÍMICA MEDICINAL: A FLEXIBILIDADE DOS LIGANTES E RECEPTORES
}

\author{
Hugo Verli* \\ Centro de Biotecnologia, Universidade Federal do Rio Grande do Sul, CP 15005, 91500-970 Porto Alegre - RS \\ Eliezer J. Barreiro \\ Faculdade de Farmácia, Universidade Federal do Rio de Janeiro, CP 68006, 21944-970 Rio de Janeiro - RJ
}

Recebido em 5/11/03; aceito em 19/7/04; publicado na web em 5/11/04

\begin{abstract}
A MEDICINAL CHEMISTRY PARADIGM: LIGANDS AND RECEPTOR FLEXIBILITY. In general, molecular modeling techniques applied in medicinal chemistry have been static and drug based. However the active site geometry and the intrinsic flexibility of both receptor and ligand are fundamental properties for molecular recognition and drug action. As a consequence, the use of dynamic models to describe the ligand-receptor complex is becoming a more common procedure. In this work we discuss the relevance of considering the receptor structure in medicinal chemistry studies as well as the flexibility of the ligandreceptor complex.
\end{abstract}

Keywords: lock and key model; induced fit; molecular dynamics.

\section{INTRODUÇÃO}

A Química Medicinal, de caráter multidisciplinar, engloba áreas como a farmacologia, a bioquímica, a química orgânica sintética e a química computacional, entre outras, na busca do desenvolvimento/ descoberta de novos fármacos ${ }^{1,2}$.

De forma geral, a aplicação da modelagem molecular na química medicinal vem seguindo abordagens "estáticas" centradas principalmente nos ligantes (fármacos, "lead-compounds", etc), sendo exemplos clássicos a $\mathrm{SAR}^{3}$ e a $\mathrm{QSAR}^{4}$. Estas estratégias de construção de modelos em química computacional sem a consideração direta das proteínas-alvo foram delimitadas, tanto pela pequena disponibilidade de estruturas 3D de receptores, quanto pelo elevado custo computacional necessário para se gerar relações quantitativas entre a estrutura e a atividade biológica, utilizando-se modelos dinâmicos. Este quadro vem se modificando com a ampliação do número de trabalhos utilizando outros tipos de metodologias capazes de produzirem modelos "dinâmicos" do complexo entre o ligante e sua proteína-alvo. Dentre estas podemos citar a QSAR-4D5, o "docking" flexível $^{6}$, a dinâmica molecular ${ }^{7-9}$ e o método de Monte Carlo ${ }^{6,10}$.

Esta mudança no perfil dos modelos gerados por modelagem molecular está sendo possibilitada principalmente pela redução do custo computacional necessário à realização destes estudos, de forma que computadores pessoais já substituem eficientemente custosas estações de trabalho. Essa busca progressiva da consideração, tanto das proteínas-alvo quanto do aspecto dinâmico do complexo fármaco-receptor nos estudos de modelagem molecular baseia-se na idéia de que a desconsideração da estrutura do receptor, juntamente com a rigidez do sistema, acarretam em modelos incapazes de descrever os processos biológicos de interesse.

Este trabalho se insere no contexto da retrospectiva da Química Medicinal no Brasil nos últimos 25 anos, traçada por Amaral e Montanari² em Química Nova, onde foram mencionados alguns desafios a serem enfrentados pelos Químicos Medicinais nos próximos anos, tais como a necessidade de que as abordagens metodológicas sejam de domínio comum (livres); a avaliação de estruturas flexíveis; a simulação da permeabilidade de membranas; a

*e-mail: hverli@cbiot.ufrgs.br predição da interação ligante-proteína; a determinação de estruturas de proteínas farmacologicamente relevantes; estratégias de superposição e alinhamento de estruturas flexíveis. O objetivo deste trabalho é, portanto, revisar a importância da estrutura do receptor e, principalmente, da flexibilidade tanto da proteína-alvo quanto do ligante no desenvolvimento de modelos computacionais úteis para o planejamento racional de novos fármacos. Com o início da "era do proteoma" após a elucidação do genoma humano, o número de estruturas 3D de biorreceptores irá aumentar progressivamente, assim como as técnicas de análise se tornarão mais ágeis, baratas e eficientes. O domínio destas ferramentas de análise se tornará cada vez mais importante no desenvolvimento de novos agentes terapêuticos. Neste sentido, esperamos que os exemplos aqui apresentados possam demonstrar a qualidade de informações sobre a ação dos ligantes estudados, que podem ser perdidas ou ganhas em função do modelo de estudo escolhido. Destacamos que estudos com modelos de membranas biológicas não serão discutidos neste trabalho ${ }^{11,12}$.

\section{A COMPLEMENTARIDADE FÁRMACO-RECEPTOR}

A noção de que as interações entre uma enzima e seu substrato seriam complementares foi introduzida, inicialmente, pelo famoso modelo "chave-fechadura", proposto por Emil Fischer, em $1894^{13}$ (Figura 1). Esta noção de complementaridade foi subseqüientemente aplicada a reações antígeno-anticorpo ${ }^{14}$ e, mais recentemente, extrapolada para a interação entre fármacos e seus respectivos receptores (e.g. receptores, enzimas e DNA $)^{3}$. Esta complementaridade, a nível molecular, seria observada através de interações intermoleculares (e.g. interações hidrofóbicas, interações de van der Waals, interações entre nuvens $\pi$, ligações de hidrogênio, interações eletrostáticas, etc.) capazes de estabilizar a energia livre do complexo fármaco-receptor ${ }^{4,15}$.

Esta noção tradicional de uma complementaridade rígida entre a "chave" e a "fechadura" foi alimentada por estudos de complexos de enzimas proteolíticas com pequenos inibidores ${ }^{16-18}$ e pelo primeiro exemplo de complexo cristalográfico proteína-anticorpo ${ }^{19}$. Além disto, as qualidades didáticas deste modelo, apresentando de modo claro e ilustrativo o reconhecimento molecular entre receptores e ligantes, tornam-no a escolha ideal para introduzir aos estudantes o processo 


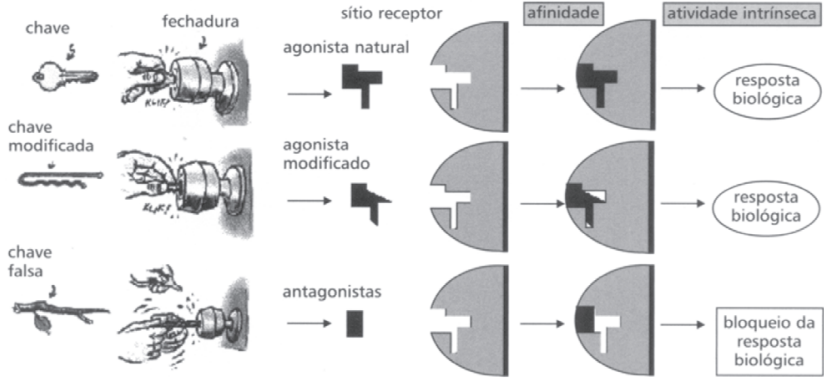

Figura 1. Representação do modelo chave-fechadura e do processo de reconhecimento do ligante por seu receptor biológico. Reproduzida da ref. 3, p. 17, Figura 1.3, com permissão da Artmed Editora S/A

de reconhecimento molecular. Além destes aspectos, pode também ilustrar de modo simplificado as diferenças entre agonistas, antagonistas e agonistas parciais (Figura 1). Contudo, induz o leitor a imaginar tanto o ligante (chave) quanto o receptor (fechadura) como entidades rígidas, o que não representa a realidade. É justamente essa flexibilidade um dos fatores que permite que moléculas estruturalmente semelhantes apresentem conformações e orientações relativas distintas no sítio de ligação do receptor e, em consequiência, atividades e afinidades também diferentes ${ }^{20}$. Um exemplo envolve os compostos 1 e 2 (Figura 2a) derivados do núcleo pirazolo[4,3d]piridina, inibidores da enzima acetilcolinesterase (AChE) e planejados $^{21}$ como análogos da tacrina (3), o primeiro composto aprovado para o tratamento sintomático do mal de Alzheimer. Estudos de dinâmica molecular indicaram, contudo, que a orientação adotada por 1,2 e 3 no sítio ativo da AChE não é semelhante, mesmo considerando-se a similaridade estrutural entre estas moléculas (Figura 2b).

A flexibilidade de proteínas e enzimas é bem conhecida, assim como as escalas de tempo nas quais ocorrem ${ }^{22}$. Além desta variabilidade conformacional intrínseca de estruturas protéicas, diversas teorias referem-se à ocorrência de mudanças conformacionais em enzimas, induzidas pelo substrato e/ou pelo ligante - inibidor, dentre as quais podemos destacar a teoria do encaixe induzido ("Induced Fit", ver adiante) ou interação flexível.

Por outro lado, a variabilidade conformacional de ligantes é um fator complicador enfrentado rotineiramente nos estudos de modelagem molecular. A etapa de análise conformacional é o primeiro passo nesses estudos, buscando identificar aquela mais estável e, idealmente, a conformação bioativa ${ }^{23,24}$.

$\mathrm{O}$ conhecimento de que tanto ligantes quanto seus receptores apresentam-se como estruturas flexíveis em escalas de tempo relativamente amplas ${ }^{25}$ nos leva a supor que o próprio tempo nos quais ocorrem as mudanças conformacionais pode ser uma propriedade importante no estudo da interação de ligantes e seus receptores, tendo sido inclusive proposta como uma quarta dimensão em análises de QSAR ${ }^{5}$. Algumas abordagens alternativas foram também propostas, tais como modelos farmacofóricos dinâmicos ${ }^{26}$.

\section{O ENCAIXE INDUZIDO}

A teoria do encaixe induzido foi desenvolvida inicialmente por Koshland e colaboradores ${ }^{27}$, baseada em sistemas enzimáticos. Esta teoria sugere que, através da complexação, o substrato induz uma mudança conformacional na subunidade da enzima com a qual interage. Esta mudança pode ser transmitida às subunidades vizinhas, induzindo na enzima a conformação responsável pelo processo catalítico ${ }^{28}$. O mesmo processo por ser aplicado à interação de inibidores com enzimas ou agonistas e antagonistas com receptores. Particularmente no caso de agonistas, ao invés da mudança conforma- a)

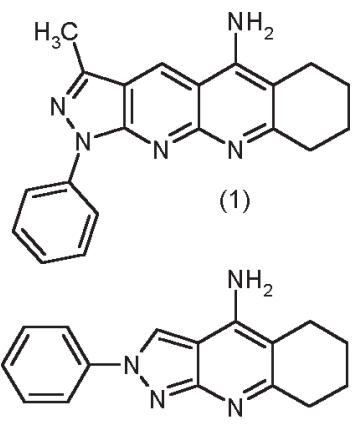

(2)

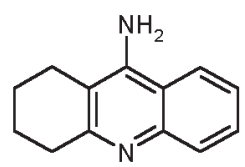

(3)

b)

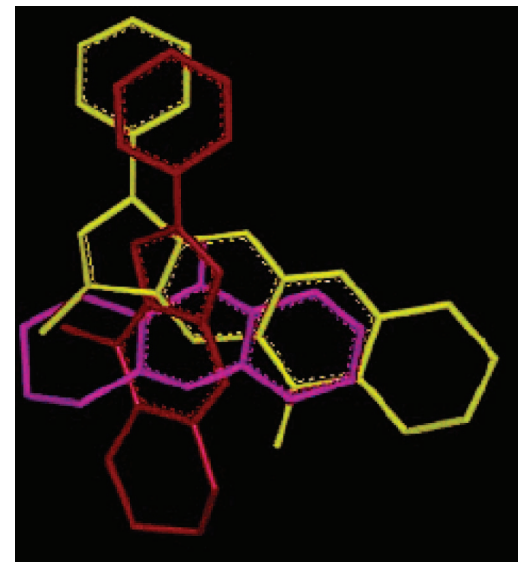

Figura 2. a) Estrutura dos compostos 1, 2 e 3; b) visão frontal dos compostos 1 (amarelo), 2 (vermelho) e 3 (rosa) orientados no sítio ativo da AChE (omitida para fins de clareza). Reproduzida da ref. 21 , com permissão da ACS

cional no receptor influenciar na catálise poderá, por exemplo, modificar a condutância de um canal iônico, e.g. benzodiazepínicos frente ao receptor $\mathrm{GABA}_{\mathrm{A}}$, um canal de íons cloreto.

Em outras palavras, a teoria do encaixe induzido considera a capacidade do ligante de selecionar ou induzir a modificação da estrutura tridimensional de seu receptor biológico, ao mesmo tempo em que este receptor tem a propriedade de reconhecer uma ou um conjunto de conformações do(s) ligante(s) ${ }^{29,30}$. Este, ao acarretar uma mudança conformacional de seu receptor, pode estar induzindo-o a adotar a conformação responsável por seu reconhecimento (Figura 3).

As mudanças conformacionais observadas como conseqüência da interação de um fármaco com seu receptor podem ser de diferentes graus de amplitude e complexidade. Podem envolver uma reorientação da cadeia lateral de um resíduo de aminoácido de forma a maximizar interações com o ligante (exemplos adiante) e, portanto, estabilizar o complexo. Em outros casos, contudo, as mudanças conformacionais são muito mais intensas e distantes do sítio de interação do ligante (e.g. a interação do pentassacarídeo sintético com a antitrombina, induzindo mudanças conformacionais a até $30 \AA^{31}$, ver adiante), sendo de difícil racionalização.

A análise do número de citações do termo "Induced Fit" (encaixe induzido) em bancos de dados indica um aumento da aplicação deste conceito em trabalhos acadêmicos, tendo-se em vista o uso crescente desta expressão na literatura científica (Figura 4). Citações em número significativo somente foram observadas a partir de, apro- 


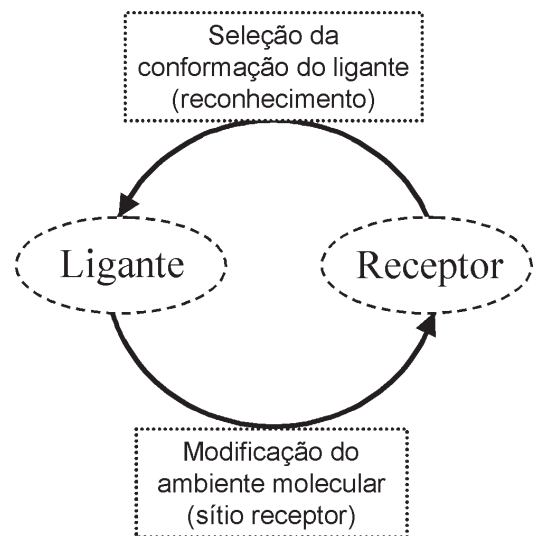

Figura 3. Esquema do processo de indução e seleção de conformações por ligante e receptor, modificando-se mutuamente no processo de interação do qual poderá resultar uma resposta de interesse terapêutico. Adaptado da ref. 30

ximadamente, 20 anos após o trabalho original de Koshland e colaboradores ${ }^{27}$. Deste então, estas citações vêm crescendo de modo bastante acelerado, mostrando a progressiva inserção do conceito nos trabalhos acadêmicos. Merece ser destacado o baixo índice de citações do termo "Induced Fit" no "Journal of Medicinal Chemistry" (índice de impacto: 4,139), o que reforça o fato de que os aspectos dinâmicos da interação fármaco-receptor ainda não foram amplamente assimilados pelos químicos medicinais.

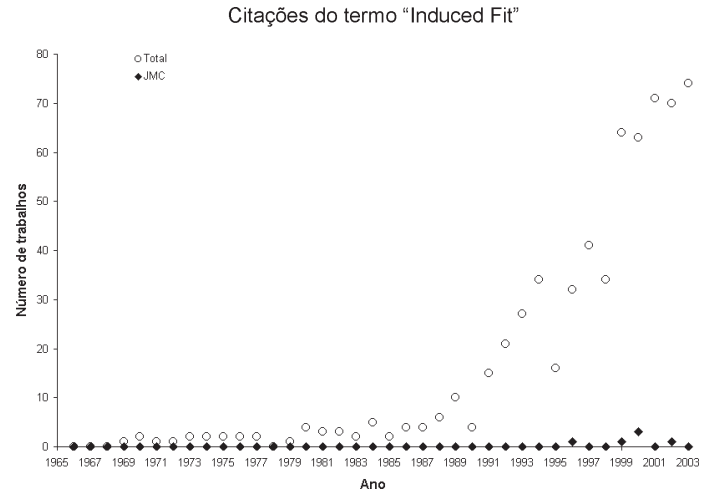

Figura 4. Número de citações do termo "Induced Fit". Total corresponde às citações encontradas no sítio Web of Science ${ }^{32}$, enquanto JMC, às citações encontradas no "Journal of Medicinal Chemistry" 33

\section{AS PROTEÍNAS SÃO ESTRUTURAS FLEXÍVEIS?}

A flexibilidade das proteínas é um fato conhecido há aproximadamente $40 \operatorname{anos}^{35}$. Os mesmos autores mencionam que “... a protein cannot be said to have 'a' secondary structure but exist mainly as a group of structures not too different from one another in free energy but frequently differing considerably in energy and entropy ..."

Hoje sabemos que as proteínas (e ácidos nucléicos) podem assumir um grande número de conformações praticamente isoenergéticas, denominadas subestados conformacionais ${ }^{36-38}$. Além disso, estas estruturas são capazes de sofrerem mudanças conformacionais induzidas pela complexação a substratos ou inibidores, sendo este tipo de mudança conformacional importante na compreensão da modulação da atividade de enzimas alostéricas por diferentes efetores ${ }^{28,38-40}$.

Sugere-se que os biorreceptores apresentam um número variado de conformações ativas ${ }^{35}$, algumas mais estáveis que outras, de modo que agonistas diferentes estabilizam populações diferentes de receptores $^{38}$. Deste modo, um agonista A pode produzir um espectro de conformações ativas, enquanto que um agonista B pode estabilizar outro conjunto de conformações do biorreceptor, processo denominado seleção conformacional. Paralelamente a este conceito e, segundo alguns autores ${ }^{38}$, permeado ao mesmo, existe o conceito de indução conformacional, segundo o qual um agonista induz uma conformação de seu receptor nunca encontrada na sua ausência ${ }^{40}$.

Os movimentos por que passam as proteínas ocorrem em uma grande variedade de escalas de tempo e de distâncias ${ }^{22,25,36}$. Estão disponíveis uma série de técnicas para avaliar estes comportamentos, onde se pode mencionar os espectros de $\mathrm{RMN}^{41}$, simulações de dinâmica molecular ${ }^{7-9}$, análise de modos normais ${ }^{42-44}$ e difração de raios- $X^{45,46}$.

Gostaríamos de destacar, dentre os métodos supracitados, as simulações por dinâmica molecular. Estas simulações vêm sendo progressivamente beneficiadas pelo ganho na velocidade de processamento dos computadores pessoais, a uma fração do preço de estações gráficas e supercomputadores. Soma-se a isto o desenvolvimento de novos programas e algoritmos mais rápidos e eficientes ${ }^{47-49}$. Desta forma criam-se condições para simulações progressivamente maiores e, assim, de melhor qualidade estatística ${ }^{50,51}$, e.g. a simulação de um peptídeo de 36 resíduos de aminoácidos por $1 \mu \mathrm{s}^{52} \mathrm{e}$ a simulação de uma aquaporina, totalizando aproximadamente 100.000 átomos $^{53}$. Ao mesmo tempo, a dificuldade de produzir relações quantitativas entre os modelos gerados e as atividades biológicas de ligantes simulados vem sendo progressivamente contornada ${ }^{54}$. As Figuras $5 \mathrm{e}$ 6 apresentam o número de citações da expressão "molecular dynamics", respectivamente, no Web of Science e no "Journal of Medicinal Chemistry", confirmando a importância crescente desta metodologia.

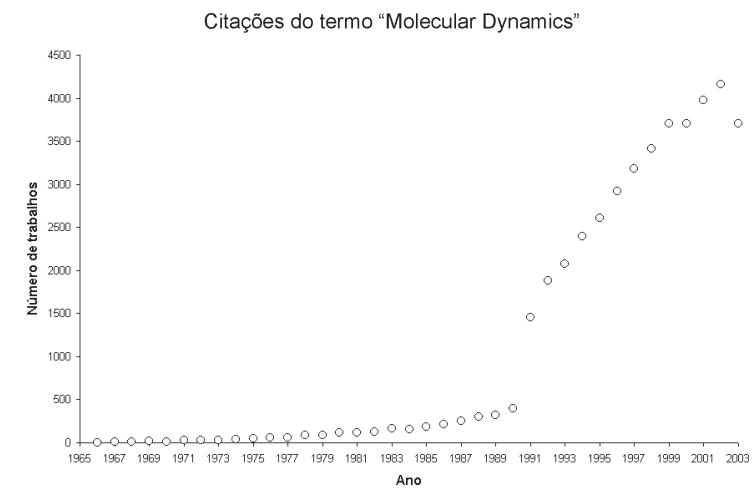

Figura 5. Número de citações do termo "Molecular Dynamics" encontradas no Web of Science $e^{32}$

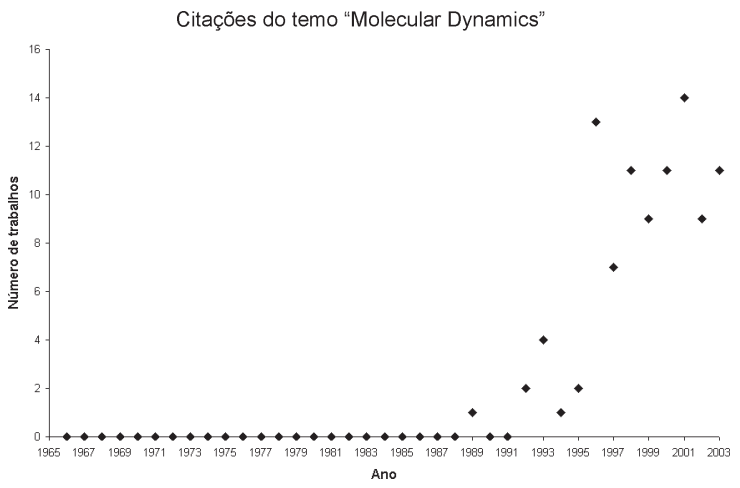

Figura 6. Número de citações do termo "Molecular Dynamics" encontradas no "Journal of Medicinal Chemistry" 
Observação da flexibilidade de proteínas em estruturas do PDB

O conhecimento dos movimentos intrínsecos de um biorreceptor não é exclusivo de bioquímicos ou biologistas estruturais. Ao contrário, o reconhecimento molecular entre fármacos e receptores será dependente das conformações de ambas as moléculas (e.g. encaixe induzido, seleção conformacional e indução conformacional). A avaliação da flexibilidade intrínseca dos fármacos é tarefa mais simples, tendo-se em vista o menor número de graus de liberdade comparativamente à estrutura protéica de seu biorreceptor. Uma vez que as simulações de dinâmica molecular ainda não podem ser realizadas em escalas de tempo muito elevadas (usualmente maiores que algumas dezenas de nanossegundos $\left.{ }^{55,56}\right)$, as coordenadas atômicas obtidas por métodos experimentais são a principal fonte de informação neste quesito ${ }^{41,45}$, além de estarem disponíveis em bancos de dados de acesso livre, como o "Protein Data Bank"

As estruturas obtidas por cristalografia, por si somente, já podem nos oferecer algumas informações sobre a dinâmica intrínseca da proteína mesmo que, no cristal, correspondam a geometrias "estáticas". Isto é observado no denominado Fator de temperatura $B_{j}$. Este fator reflete dois tipos de propriedades do átomo j: movimentos térmicos e desordem. Os movimentos térmicos de um dado átomo estão associados à sua vibração em relação a uma posição de repouso na estrutura cristalina, enquanto a desordem se refere a um átomo ou grupo de átomos que não ocupam a mesma posição em cada célula unitária, em cada unidade assimétrica ou em cada molécula dentro de uma unidade assimétrica do cristal ${ }^{58}$.

Contudo, o modo mais usual de observar as mudanças conformacionais de proteínas - encaixe induzido - utilizando-se estruturas cristalográficas é comparando-se diferentes cristais de uma mesma proteína complexada a diferentes inibidores e/ou substratos. Um exemplo bastante ilustrativo é um trabalho recente de Zoete e colaboradores comparando diferentes estruturas cristalográficas da protease de $\mathrm{HIV}^{59}$. Através da comparação de 73 estruturas cristalográficas, variando-se os inibidores complexados e mutações, assim como o uso de métodos teóricos (e.g. dinâmica molecular e modos normais), os autores conseguem traçar um mapa da flexibilidade intrínseca da protease de HIV sob diversas condições. Essas informações puderam ser utilizadas na análise das possíveis causas moleculares para a resistência a fármacos em enzimas mutantes.

Análises mais localizadas e rápidas podem também ser realizadas, oferecendo informações importantes para o químico medicinal. Um exemplo envolve a sobreposição de três estruturas cristalográficas da enzima acetilcolinesterase (AChE) complexadas aos inibidores tacrina (3), galantamina (4) e donezepil (5) (Figura 7). Após a sobreposição, pode-se evidenciar que a cadeia lateral de um resíduo do sítio ativo da enzima, Phe330, apresenta-se em orientação distinta nos complexos (Figura 8). Esta orientação distinta deve ser levada em conta no momento de complexarmos os inibidores estudados planejados, sob pena de eliminarmos interações importantes ou, pior, adicionarmos repulsão no sistema, comprometendo os resultados.

As mudanças na estrutura cristalográfica de uma dada proteína/ enzima, em decorrência da complexação a um ligante/inibidor, podem envolver também transformações maiores na estrutura terciária da proteína. Um exemplo envolve a antitrombina (AT), uma proteína plasmática relacionada com a inibição de serino-proteinases da cascata de coagulação ${ }^{31}$. Essa proteína, quando na forma livre (Figura $9 b$ ), é relativamente inativa como inibidora. Contudo, ao se ligar à heparina ou a um pentassacarídeo sintético (6, Figura 9a), apresenta grandes mudanças conformacionais que a tornam um inibidor do fator Xa da coagulação, 300 vezes mais eficiente (Figura 9c). Dentre essas mudanças, são observados movimentos de cadeias por até 17 A (formação de $\alpha$-hélice, marcada por um círculo verde na Figura

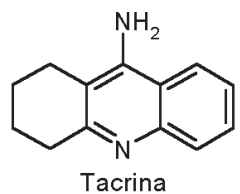

(3)

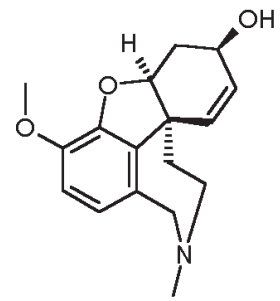

Galantamina

(4)

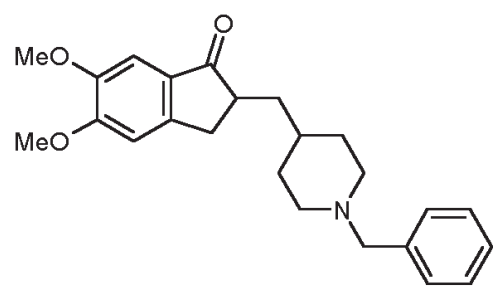

Donezepil

(5)
Figura 7. Estruturas dos compostos 3, 4 e 5

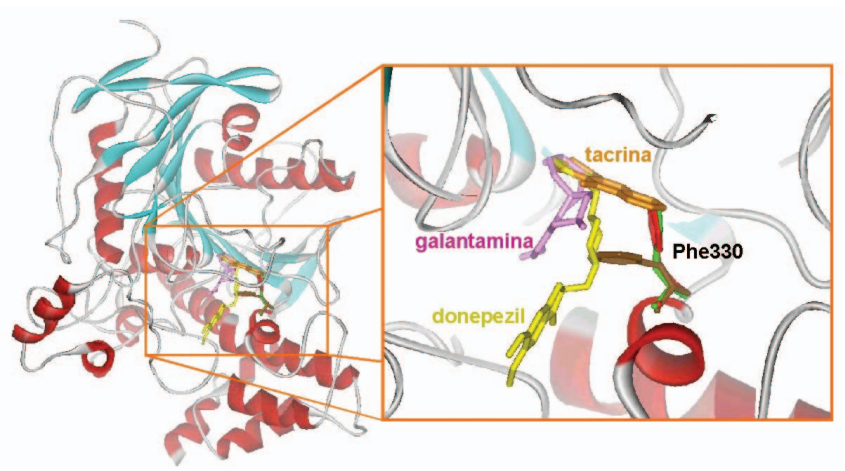

Figura 8. Complexos sobrepostos da enzima AChE com os compostos 3 , 4 e 5 (obtidos, respectivamente, pelos códigos PDB 1ACJ, 1DX6 e 1EVE), demonstrando a variação da orientação da cadeia lateral do resíduo Phe330

9), além de outros movimentos notados a 30 Å do sítio de ligação de 6 (mudanças conformacionais de folhas- $\beta$ e alças, marcadas por um círculo vermelho na Figura 9), sugerindo um complexo mecanismo alostérico. É importante notar que o composto 6 não é um inibidor, mas um modulador que aumenta a atividade inibitória da AT e que já se encontra em testes clínicos.

\section{EXEMPLOS DE ENCAIXE INDUZIDO}

Um exemplo de encaixe induzido entre um análogo da neocarzinostatina (7, Figura 10), composto com atividade antibiótica e antitumoral, e seu sítio de ligação no DNA é descrito ${ }^{60}$. Os autores utilizaram o método de dicroísmo circular (DC) que, ao medir diferenças na absorção da luz polarizada pelo sistema em estudo, pode indicar tanto a natureza da estrutura secundária de proteínas e/ou DNA quanto o grau de modificação conformacional induzida pelo ligante. A comparação dos espectros de DC do DNA isolado em solução e do DNA complexado ao composto 7 demonstra significativas mudanças conformacionais no DNA induzidas por 7. Esta capacidade do ligante (composto 7) de modificar a conformação de seu receptor-alvo (DNA) é indicativa do processo de encaixe induzido e não de uma complementaridade rígida do tipo chave-fechadura. Segundo os autores, o encaixe induzido observado parece ser consequiência direta da otimização de contatos de van der Waals e de ligação hidrogênio com as paredes da região de ligação no DNA. Estas interações, energeticamente favoráveis, provavelmente provêem a energia necessária para as mudanças conformacionais tanto no 
a)

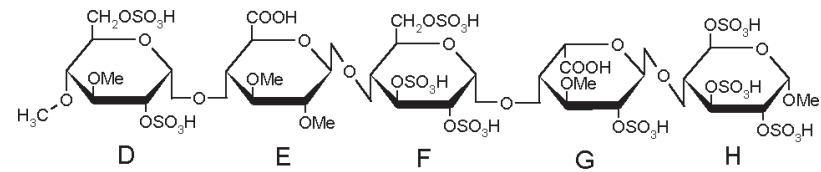

(6) b)

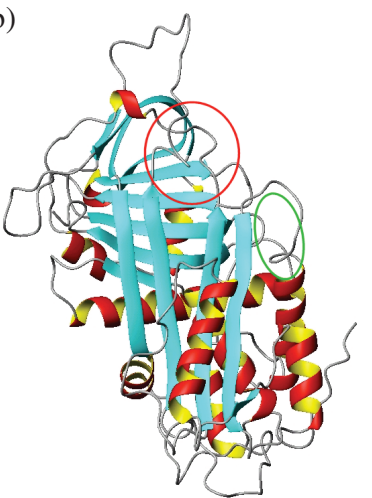

c)

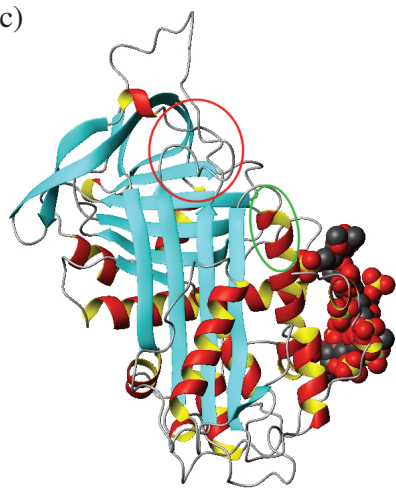

Figura 9. a) estrutura do composto 6; b) forma livre da AT (código PDB 1ANT); c) forma da AT ligada a 6 (código PDB 1AZX), apresentando formação de $\alpha$-hélice (círculo verde) e mudanças conformacionais de folhas$\beta$ e alças (círculo vermelho)<smiles>CN[C@@H]1[C@H](C)O[C@H](O)[C@H](O)[C@@H]1O</smiles>

Neocarzinostatina

(7)

Figura 10. Estrutura do composto 7

ligante quanto no DNA (receptor) e, desta forma, correspondem à fonte de estabilidade do complexo entre 7 e o DNA.

Este perfil de flexibilidade da interação de antibióticos antitumorais com o DNA é também descrito para outros compostos, como a esperamicina ${ }^{61}$ (8, Figura 11). Este trabalho identifica, primeiramente, a ocorrência de distorção estrutural no DNA quando complexado a 8. Considerando-se então a modificação estrutural do DNA como um fator importante e requerido para a ligação de 8 , os autores avaliaram como o aumento da rigidez do oligonucleotídeo utilizado afetaria a constante de ligação. Foi verificado, desta forma, que quanto mais rígido o oligonucleotídeo, menor a afinidade de 8 pela seqüência de DNA. Soma-se a isto o fato de que o uso de solventes orgânicos levou a significativo aumento da afinidade, o que indica que os aspectos hidrofóbicos são predominantes no processo.

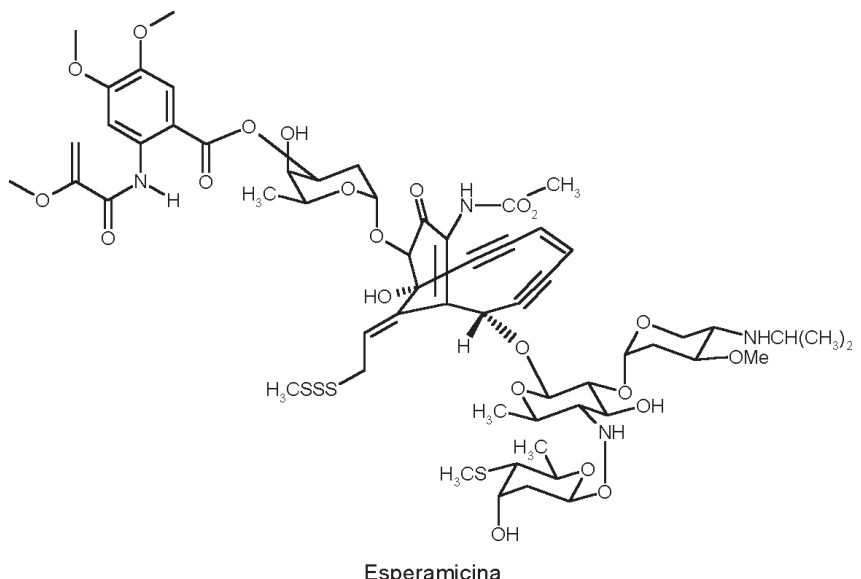

(8)

Figura 11. Estrutura do composto 8

Usón e colaboradores ${ }^{62}$ descreveram um exemplo característico de inibidores possuindo elevado grau de flexibilidade, necessário para o reconhecimento por sua enzima alvo, adotando um encaixe induzido. Trata-se da hirustasina, um peptídeo inibidor de serinoproteinases, obtido da sanguessuga Hirudo medicinalis. A comparação entre as estruturas da hirustasina livre e complexada à enzima kalikreína demonstra que a formação deste complexo acarreta no movimento da região N-terminal do inibidor (Figura 12). Tal flexibilidade intrínseca, mesmo apresentando a hirustasina 5 ligações dissulfeto em sua cadeia, é necessária para que o inibidor adote a conformação ideal para seu reconhecimento pelas proteases da cascata da coagulação.

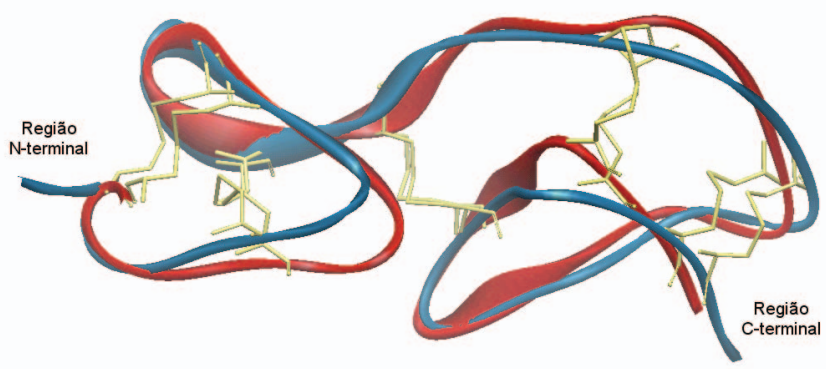

Figura 12. Sobreposição da estrutura da hirustasina livre (código PDB 1BX7, em azul) e complexada à kalikreína (código PDB 1HIA, em vermelho), enzima omitida para fins de clareza. As ligações dissulfeto estão apresentadas em amarelo

Este tipo de evidência nos leva a confrontar a semelhança entre as estruturas tridimensionais de proteínas determinadas por métodos de cristalografia e as estruturas em solução. De modo geral, ambas são equivalentes ${ }^{28}$. Contudo, nos casos em que ocorre um equilíbrio entre diferentes conformações de uma enzima em solução, a cristalografia pode selecionar somente uma destas conformações ${ }^{28}$. Um exemplo deste processo ocorre com a glicogênio fosforilase $b$. Neste caso, o efeito de um modulador alostérico na modificação da estrutura da enzima é visto somente em solução, não ocorrendo na estrutura cristalina ${ }^{63}$

Os modelos rígidos utilizados no entendimento da interação fármaco-receptor freqüentemente nos levam a realizar interpretações simplificadas do processo de reconhecimento molecular e, por conseguinte, a nos equivocarmos quanto ao possível perfil de atividade de um dado composto. Um exemplo bastante ilustrativo foi relatado 
quanto a inibidores de metaloproteinases de matriz celular. Estes inibidores, constituindo-se em estruturas peptídicas (como o composto 9, Figura 13), apresentam biodisponibilidade e meia-vida plasmática limitadas. Desta forma, Rockwell e colaboradores ${ }^{64}$ utilizaram métodos de química combinatorial buscando modificações na estrutura do peptídeo, de forma a produzir os perfis farmacocinéticos mais adequados. Dentre as estruturas produzidas encontra-se o composto 10 , cujo perfil de atividade não pôde ser explicado pelos modelos utilizados pelo grupo. Havia dificuldade em encontrar sítios de ligação capazes de acomodar os anéis fenila introduzidos no composto 10. A determinação da estrutura cristalográfica de ambos os complexos indicou que, no complexo de 10, uma alça da proteína (resíduos 222-231) sofre uma mudança conformacional inesperada, permitindo a acomodação dos anéis fenila, mesmo com a perda de duas ligações hidrogênio em relação ao complexo de 9. O exame cuidadoso das interações entre a enzima e 10 permitiu ainda a adição de um aceptor de ligação hidrogênio (compostos isoméricos $11 \mathrm{e}$ 12), modificação esta que determinou, para um dos diastereoisômeros formados, um aumento de afinidade de 16 vezes em relação a 10.

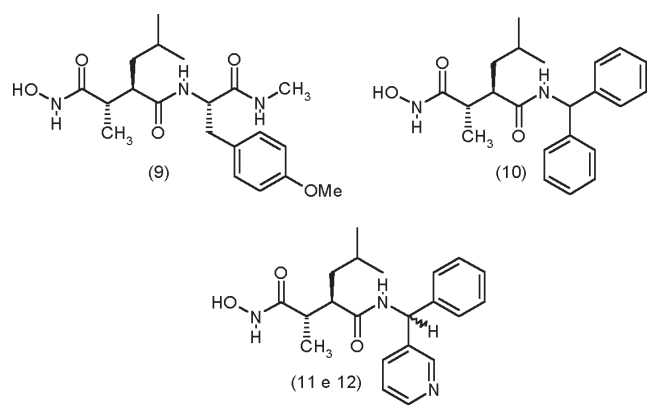

Figura 13. Estruturas dos compostos 9-12

\section{HIV Protease}

A Síndrome da Imunodeficiência Adquirida (AIDS/SIDA) foi a primeira grande epidemia causada por um patógeno até então desconhecido durante o século XX, justamente o período correspondente ao desenvolvimento das ciências farmacêuticas modernas ${ }^{65}$. A ausência completa de agentes capazes de tratar a doença tornou necessário o desenvolvimento de agentes terapêuticos completamente novos. Esta necessidade, juntamente com o rápido progresso na compreensão da estrutura e do ciclo de vida virais, levou a um desenvolvimento sem precedentes de novos fármacos agindo sobre diversas proteínas virais, e.g. transcriptase reversa, integrase e protease (HIVprotease).

A HIV-protease é uma enzima homodimérica, responsável pelo processamento das poliproteínas virais Gag e Pol em proteínas e enzimas estruturalmente maduras, necessárias para o ciclo de vida do HIV ${ }^{66,67}$. A inibição desta enzima acarreta a produção de partículas virais não-funcionais e não-infecciosas ${ }^{68}$.

A descoberta e o desenvolvimento de inibidores de HIV-protease constituiram-se num sucesso absoluto da farmacologia e da biologia estrutural modernas ${ }^{65}$. É um dos melhores exemplos de planejamento de fármacos ("structure-based drug design" ou planejamento de fármacos baseado na estrutura do receptor) utilizando-se metodologias como cristalografia, RMN e modelagem molecular, de forma a guiar a síntese de novos agentes terapêuticos.

O saquinavir (13, Figura 14), desenvolvido pela Hoffmann-La Roche, foi primeiro fármaco inibidor da HIV-protease aprovado pelo FDA. Seu desenvolvimento, contudo, foi acompanhado somente de estudos estruturais limitados. Em contrapartida a Merck, no desenvolvimento do indinavir (14, Figura 14), guiou-se por estudos de modelagem molecular e pela determinação da estrutura cristalográfica do complexo enzima-inibidor ${ }^{69,70}$.

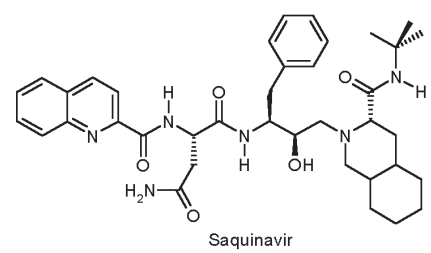

(13)

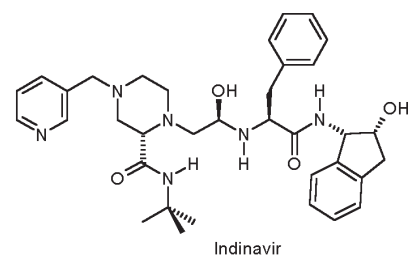

(14)

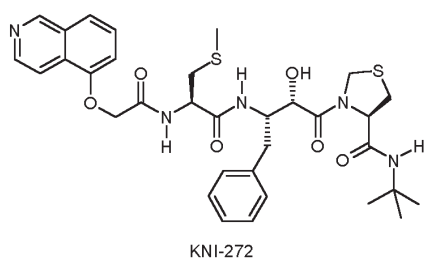

(15)

Figura 14. Estruturas dos compostos 13, 14 e 15

O surgimento de mutantes de HIV-protease resistentes aos atuais inibidores tem mantido o interesse e a necessidade do desenvolvimento de novos compostos ativos contra as cepas de vírus resistentes. Contudo, as tentativas de explicar a atividade catalítica da HIV-protease foram inicialmente baseadas em estruturas estáticas da proteína, obtidas por cristalografia. Estes estudos foram incapazes de descrever a resistência de enzimas apresentando mutações com propriedades eletrostáticas semelhantes ou distantes do sítio catalítico da enzima, de forma que um grande número de estudos vem se preocupando em analisar as propriedades dinâmicas desta enzima, o que pode auxiliar no desenvolvimento de novos inibidores ${ }^{59,71-73}$.

A importância do conhecimento da dinâmica intrínseca da HIVprotease pode ser exemplificada pelo fato de que espectros de RMN da mesma com inibidores simétricos não permitem a diferenciação dos sinais dos dois monômeros ${ }^{74}$. Contudo, o uso de espectros HSQC ${ }^{1} \mathrm{H}-{ }^{15} \mathrm{~N}$ para o complexo da HIV-protease com o inibidor assimétrico KNI-272 (15, Figura 14) ilustra claramente que as interações do inibidor com cada um dos monômeros da enzima são distintas ${ }^{71}$. Além disto, o trabalho evidenciou que, mesmo sendo o esqueleto peptídico da enzima bastante rígido, diversos segmentos da cadeia polipeptídica são flexíveis, com destaque para a ponta das abas que envolvem o sítio ativo da protease. No cômputo global, a flexibilidade é maior no monômero 1 que no monômero 2, sugerindo que a flexibilidade (e a geometria) do esqueleto polipeptídico é sensível às diferentes interações realizadas com o composto 15 .

Estas abas, que se localizam ao redor do sítio ativo da enzima, supostamente abrem-se em solução, de modo que a proteína a ser hidrolisada possa ter acesso ao sítio catalítico da enzima. Estudos anteriores descreveram estas abas como alavancas rígidas controlando o acesso ao sítio catalítico ${ }^{75}$, o que não está de acordo com a flexibilidade já descrita destes resíduos de aminoácidos ${ }^{71}$.

Enquanto experimentos de relaxação de RMN podem determinar as taxas globais segundo as quais as regiões de proteínas se movem, eles não podem gerar detalhes do papel que átomos individuais exercem no movimento observado ${ }^{72}$. O conhecimento destes detalhes em nível atômico é essencial não somente na compreensão do processo de reconhecimento de substratos, mas também na compreensão do porquê mutações em sítios nas abas, ou ao redor destas, podem conferir resistência a fármacos ${ }^{76}$.

Neste sentido, o trabalho de Scott e Schiffer ${ }^{72}$, utilizando dinâmica molecular, descreve como ocorre o movimento das abas ao redor do sítio ativo da protease de HIV-1. As simulações realizadas pelos autores foram capazes de descrever a abertura das abas a partir de $5 \mathrm{~ns}$ 
para a enzima livre. O mesmo não ocorreu com a enzima complexada a um substrato, deixando claro que a flexibilidade da enzima é influenciada pelo ligante. Tendo-se em vista a dificuldade de confrontar estas conformações obtidas por dinâmica molecular com dados experimentais, os autores verificaram a correlação das informações obtidas com dados de mutagênese reportados previamente. Foi identificado que resíduos em regiões funcionalmente importantes para o movimento das abas não são modificados in vitro, sem que haja comprometimento da atividade enzimática. Isto abre o precedente, segundo os autores, para o planejamento de fármacos visando estas regiões da protease, tendo-se em vista que seriam menos susceptíveis a mutações.

\section{CONCLUSÕES}

A modelização da interação entre ligantes e receptores, segundo uma abordagem rígida, retira no mínimo uma das variáveis associadas ao reconhecimento molecular de ambas as moléculas. Esta simplificação poderá acarretar em problemas dependendo da relevância desta variável para o problema estudado. Certamente, a omissão da flexibilidade do sistema reduz o espectro de informações que podem ser obtidas acerca do complexo ligante-receptor.

Neste sentindo, a modelagem molecular tem se apresentado como ferramenta importante no estudo da interação de ligantes e receptores. Exemplos de planejamento de fármacos utilizando técnicas de modelagem molecular, tais como os inibidores de protease de HIV, vêm comprovando o potencial destas metodologias no desenvolvimento de novas substâncias bioativas. A quantificação da energia de interação entre moléculas e suas proteínas-alvo, a determinação de relações quantitativas entre a estrutura química e a atividade biológica, a proposição de sítios, orientações e conformações putativos de interação de ligantes ainda não co-cristalizados e a observação do comportamento dinâmico de moléculas e complexos de interesse farmacológicos podem ser citadas como algumas das áreas nas quais a modelagem molecular vem contribuindo para a química medicinal e o planejamento de novos fármacos.

Soma-se a isto o fato de que o contínuo desenvolvimento de computadores cada vez mais rápidos e de programas mais eficientes vem tornando possível o aumento da velocidade com que estas questões são respondidas pela modelagem, assim como a abordagem de novos problemas (e.g. proposição da estrutura 3D de proteínas a partir da seqüência primária).

Poderíamos, para resumir a importância do exposto, citar frase de Jorgensen ${ }^{39}$ : "Estes exemplos confirmam a expectativa de que moléculas flexíveis se distorcem de forma a realizarem interações ótimas com seu sítio de ligação. Uma consequiência prática disto é a frustração que poderá acompanhar as tentativas de planejar fármacos em analogia a estruturas flexíveis, substâncias ativas não-ligadas.”

\section{AGRADECIMENTOS}

Os autores agradecem à CAPES, ao CNPq, à FAPERJ e à FAPERGS pelo auxílio financeiro, ao Prof. C. M. R. Sant'Anna (UFRJ - LASSBio) pelas contribuições à elaboração deste trabalho e ao Prof. J. A. Guimarães (Centro de Biotecnologia - UFRGS).

\section{REFERÊNCIAS}

1. Barreiro, E. J.; Rodrigues, C. R.; Albuquerque, M. G.; Sant'Anna, C. M. R.; Alencastro, R. B.; Quim. Nova 1997, 20, 300.

2. Amaral, A. T. do; Montanari, C. A.; Quim. Nova 2002, 25 - Supl. 1, 39.

3. Barreiro, E. J.; Fraga, C. A. M.; Química Medicinal: as bases moleculares da ação dos fármacos, Artmed Ed. Ltda: Porto Alegre, 2001.

4. Kubinyi, H.; QSAR: Hansch analysis and related approaches. Methods and principles in medicinal chemistry, VHC: Weinheim, 1993.
5. Albuquerque, M. G.; Hopfinger, A. J.; Barreiro, E. J.; de Alencastro, R. B.; J. Chem. Inf. Comput. Sci. 1998, 38, 925.

6. Rosenfeld, R.; Vajda, S.; Delisi, C.; Annu. Rev. Biophys. Biomol. Struct. 1995, 24, 677 .

7. Daggett, V.; Levitt, M.; Ann. Rev. Biophys. Biomol. Struct. 1993, 22, 353.

8. van Gunsteren, W. F.; Luque, F. J.; Timms, D.; Torda, A. E.; Annu. Rev. Biophys. Biomol. Struct. 1994, 23, 847.

9. Hansson, T.; Oostenbrink, C.; van Gunsteren, W. F.; Curr. Opin. Struct. Biol. 2002, 12, 190.

10. Sant'Anna, C. M. R. de; Quim. Nova 2002, 25, 505.

11. Bowie, J. U.; Curr. Opin. Struct. Biol. 2000, 10, 435.

12. Forrest, L. R.; Sansom, M. S. P.; Curr. Opin. Struct. Biol. 2000, 10, 174.

13. Fischer, E.; Ber. Dt. Chem. Ges. 1894, 27, 2985.

14. Landsteiner, K.; The specificity of serological reactions, $2^{\text {nd }}$ ed., Harvard University Press: Cambridge, MA, 1945.

15. Böhm, H-J; Klebe, G.; Angew. Chem., Int. Ed. 1996, 35, 2588.

16. Blow, D. M.; Acc. Chem. Res. 1976, 9, 145.

17. Huber, R.; Bode, W.; Acc. Chem. Res. 1978, 11, 114.

18. Hubbard, S. J.; Campbell, S. F.; Thornton, J. M.; J. Mol. Biol. 1991, 220, 507.

19. Amit, A. G.; Mariuzza, R. A.; Phillips, S. E. V.; Poljak, R. J.; Science 1986, $233,747$.

20. Kubinyi, H.; J. Braz. Chem. Soc. 2002, 13, 717.

21. Barreiro, E. J.; Camara, C. A.; Verli, H.; Brazil-Más, L.; Castro, N. G.; Cintra, W. M.; Aracava, Y.; Rodrigues, C. R.; Fraga. C. A. M.; J. Med. Chem. 2003, 46, 1144.

22. Brooks III, C. L.; Karplus, M.; Pettitt, B. M.; Proteins: a theoretical perspective of dynamics, structure, and thermodynamics, John Wiley \& Sons: New York, 1988.

23. Itai, A.; Mizutani, M. Y.; Nishibata, Y.; Tomioka, N. Em Guidebook on Molecular Modeling in Drug Design; Cohen, N. C., ed.; Academic Press: San Diego, 1996, cap. 4.

24. Leach, A. R.; Molecular modelling: principles and applications, Longman Press: Singapore, 1996.

25. Carter Jr., C. W. Em Bioorganic chemistry: peptides and proteins; Hecht, S. M., ed.; Oxford Press: New York, 1996.

26. Carlson, H. A.; Masukawa, K. M.; Rubins, K.; Bushman, F. D.; Jorgensen, W. L.; Lins, R. D.; Briggs, J. M.; McCammon, J. A.; J. Med. Chem. 2000, 43,2100 .

27. Koshland Jr., D. E.; Neméthy, G.; Filmer, D.; Biochemistry 1966, 5, 365.

28. Fersht, A.; Structure and mechanism in protein science: a guide to enzyme catalysis and protein folding, Freeman: New York, 1998, p. 295.

29. Davis, A. M.; Teague, S. J.; Angew. Chem., Int. Ed. 1999, 38, 736.

30. Testa, B.; Bojarski, A. J.; Eur. J. Pharm. Sci. 2000, 11 Suppl. 2, S3.

31. Jin, L.; Abrahams, J. P.; Skinner, R.; Petitou, M.; Pike, R. N.; Carrell, R. W.; Proc. Natl. Acad. Sci. U.S.A. 1997, 94, 14683.

32. http://webofscience.com, acessada em Outubro 2003.

33. http://pubs.acs.org/journals/jmcmar, acessada em Outubro 2003.

34. http://www.uspto.gov/patft/index.html, acessada em Outubro 2003

35. Lindstrom-Lang, K. U.; Schellman, J. A.; Enzymes 1959, 1, 443.

36. Karplus, M.; Petsko, G. A.; Nature 1990, 347, 631.

37. Frauenfelder, H.; Sligar, S. G.; Wolynes, P. G.; Science 1991, 254, 1598.

38. Kenakin, T.; Trends Pharmacol. Sci. 1996, 17, 190.

39. Jorgensen, W. L.; Science 1991, 254, 954.

40. Bruns, R.; Trends Pharmacol. Sci. 1996, 17, 189.

41. Campbell, A. P.; Sykes, B. D.; Annu. Rev. Biophys. Biomol. Struct. 1993, 22,99 .

42. Miller, D. W.; Agard, D. A.; J. Mol. Biol. 1999, 286, 267.

43. ben-Avraham, D.; Tirion, M. M.; Physica A 1998, 249, 415.

44. Soejima, K.; Kurihara, Y.; Kamiya, K.; Umeyama, H.; FEBS Lett. 1999, 463, 19.

45. Hadju, J.; Andersson, I.; Annu. Rev. Biophys. Biomol. Struct. 1993, 22, 467.

46. Bolduc, J. M.; Dyer, D. H.; Scott, W. G.; Singer, P.; Sweet, R. M.; Koshland Jr., D. E.; Stoddard, B. L.; Science 1995, 268, 1312.

47. Berendsen, H. J. C.; van der Spoel, D.; van Drunen, R.; Comput. Phys. Commun. 1995, 91, 43.

48. Lindahl, E.; Hess, B.; van der Spoel, D.; J. Mol. Graphics Modell. 2001, 7, 306.

49. http://www.gromacs.org, acessada em Outubro 2003.

50. van Gunsteren, W. F.; Berendsen, H. J. C.; Angew. Chem., Int. Ed. 1990, 29, 992.

51. van Gunsteren, W. F.; Mark, A. E.; J. Chem. Phys. 1998, 108, 6109

52. Duan, Y.; Kollman, P. A.; Science 1998, 282, 740.

53. de Groot, Bert L.; Grubmüller, H.; Science 2001, 294, 2353.

54. Kalra, P.; Reddy, V.; Jayaram, B.; J. Med. Chem. 2001, 44, 4325.

55. Doniach, S.; Eastman, P.; Curr. Opin. Struct. Biol. 1999, 9, 157.

56. Daggett, V.; Curr. Opin. Struct. Biol. 2000, 10, 160. 
57. http://www.rcsb.org/pdb, acessada em Outubro 2003

58. Rhodes, G.; Crystallography made clear: a guide for users of molecular models, $2^{\text {nd }}$ ed., Academic Press: San Diego, 2000.

59. Zoete, V.; Michelin, O.; Karplus, M.; J. Mol. Biol. 2002, 315, 21.

60. Yang, C. F.; Jackson, P. J.; Xi, Z.; Goldberg, I. H.; Bioorg. Med. Chem. 2002, 10, 1329 .

61. Uesugi, M.; Kusakabe, T.; Sugiura, Y.; Biochim. Biophys. Acta 1995, 1261, 99.

62. Usón, I.; Sheldrick, G. M.; La Fortelle, E.; Bricogne, G.; Di Marco, S.; Priestle, J. P.; Grütter, M. G.; Mittl, P. R. E.; Structure 1999, 7, 55.

63. Johnson, L. N.; Stura, E. A.; Wilson, K. S.; Sansom, M. S. P.; Weber, I. T.; J. Mol. Biol. 1979, 134, 639.

64. Rockwell, A.; Melden, M.; Copeland, R. A.; Hardman, K.; Decicco, C. P.; DeGrado, W. F.; J. Am. Chem. Soc. 1996, 118, 10337.

65. Wlodawer, A.; Vondrasek, J.; Annu. Rev. Biophys. Biomol. Struct. 1998, 27, 249.

66. Huff, J. R.; J. Med. Chem. 1991, 34, 2305.

67. Debouck, C.; AIDS 1992, 8, 153

68. Kohl, N. E.; Emini, E. A.; Schleif, W. A.; Davis, L. J.; Heimbach, J. C.; Dixon, R. A. F.; Scolnick, E. M.; Sigal, I. S.; Proc. Natl. Acad. Sci. U.S.A. 1988, 85,4686 .
69. Dorsey, B. D.; Levin, R. B.; McDaniel, S. L.; Vacca, J. P.; Guare, J. P.; Darke, P. L.; Zugay, J. A.; Emini, E. A.; Schleif, W. A.; Quintero, J. C.; Lin, J. H.; Chen, I.-W.; Holloway, M. K.; Fitzgerald, P. M. D.; Axel, M. G.; Ostovic, D.; Anderson, P. S.; Huff, J. R.; J. Med. Chem. 1994, 37, 3443. 70. Vacca, J. P.; Dorsey, B. D.; Schleif, W. A.; Levin, R. B.; McDaniel, S. L.; Darke, P. L.; Zugay, J.; Quintero, J. C.; Blahy, O. M.; Roth, E.; Sardana, V. V.; Schlabach, A. J.; Graham, P. I.; Condra, J. H.; Gotlib, L.; Holloway, M. K.; Lin, J.; Chen, I.-W.; Vastag, K.; Ostovic, D.; Anderson, P. S.; Emini, E. A.; Huff, J. R.; Proc. Natl. Acad. Sci. U.S.A. 1994, 91, 4096

71. Freedberg, D. I.; Wang, Y-X.; Stahl, S. J.; Kaufman, J. D.; Wingfield, P. T.; Kiso, Y.; Torchia, D. A.; J. Am. Chem. Soc. 1998, 120, 7916.

72. Scott, W. R. P.; Schiffer, C. A.; Structure 2000, 8, 1259.

73. Piana, S.; Carloni, P.; Parrinello, M.; J. Mol. Biol. 2002, 319, 567.

74. Nicholson, L. K.; Yamazaki, T.; Torchia, D. A.; Grzesiek, S.; Bax, A.; Stahl, S. J.; Kaufman, J. D.; Wingfield, P. T.; Lam, P. Y. S.; Jadhav, P. K.; Hodge, C. N.; Domaille, P. J.; Chang, C. W.; Nat. Struct. Biol. 1995, 2, 274.

75. Collins, J. R.; Burt, S. K.; Erickson, J. W.; Nat. Struct. Biol. 1995, 2, 334.

76. Shao, W.; Everitt, L.; Manchester, M.; Loeb, D. D.; Hutchison, C. A.; Swanstrom, R.; Proc. Natl. Acad. Sci. U.S.A. 1997, 94, 2243. 